\title{
DNA hypermethylation of zygote arrest 1 (ZAR1) in hepatitis $C$ virus positive related hepatocellular carcinoma
}

Keiko Takagi ${ }^{1}$, Kyoko Fujiwara ${ }^{2,3^{*}}$, Tadatoshi Takayama ${ }^{1,2}$, Takao Mamiya ${ }^{1}$, Masayoshi Soma ${ }^{2,3}$ and Hiroki Nagase ${ }^{2,4}$

\begin{abstract}
Background: Hepatocellular carcinoma (HCC) is one of the most common human malignancies in the world, and its prognosis is generally poor. Epigenetic alteration such as DNA methylation has been shown to be important in the development of human cancers including HCC. Here, we analyzed the methylation status of ZAR1, which has been reported to be aberrantly methylated in a few human cancers.
\end{abstract}

Methods: We investigated the methylation status of ZAR1 in 88 HCV-positive HCC and matched nontumorous liver tissue samples and 4 normal liver tissue samples used as a control using MassARRAY EpiTYPER. Further statistical analysis was performed to determine the relationship between methylation level and patient clinicopathological features and prognosis.

Results: CpG islands in ZAR1 exon 1 showed a higher methylation level in all $88 \mathrm{HCC}$ than in nontumorous tissues. The hypermethylation group, whose cancer tissues showed a twofold or higher methylation level compared with nontumorous tissues, showed a significantly higher serum AFP $(p=0.018)$ and lower serum albumin $(p=0.001)$ and single rather than multiple tumors $(p=0.031)$ compared with the hypomethylation group. Multivariate regression analyses were performed to identify which of the following factors were the predictors of the hypermethylation group: serum albumin, AFP, and tumor multiplicity. This study showed that patients who had Zar1 hypermethylation in the HCC tissues had a significantly lower serum albumin level than those in the hypomethylation group $(p=0.007)$.

Conclusion: Although it is still unknown how ZAR1 hypermethylation affects HCC development, it could be a potential marker to detect HCV-related HCC.

Keywords: Hepatocellular carcinoma, Hepatitis C virus, Methylation

\section{Background}

Hepatocellular carcinoma (HCC) is one of the most common human malignancies in the world. Despite the fact that diagnosis and treatment have been established for $\mathrm{HCC}$, the prognosis is generally poor. Even after liver resection, $25 \%, 50 \%$, and $80 \%$ of HCC patients suffer relapses within 1, 2, and 5 years, respectively. Although

\footnotetext{
* Correspondence: fujiwara.kyoko@nihon-u.ac.jp

${ }^{2}$ Innovative Therapy Research Group, Nihon University Research Institute of Medical Science, Nihon University School of Medicine, 30-1 OyaguchiKamicho, Itabashi-ku, Tokyo 173-8610, Japan

${ }^{3}$ Division of General Medicine, Department of Medicine, Nihon University School of Medicine, 30-1 Oyaguchi-Kamicho, Itabashi-ku, Tokyo 173-8610, Japan

Full list of author information is available at the end of the article
}

the incidence of nonBnonC-HCC has recently shown an increasing trend, there still are many HCV-positive HCC patients in Japan (Ikai et al. 2007; Makuuchi et al. 1998). Although the molecular mechanisms of its pathogenesis remain unclear, epigenetic alteration such as DNA methylation has been shown to play an important role in the development of human cancers (Shinojima et al. 2010; Kawashima et al. 2012; Watanabe et al. 2011). In addition, aberrant DNA methylation of promoter CpG islands of many genes has been reported for HCC. Methylation of promoter $\mathrm{CpG}$ islands of the tumor suppressor genes has been reported. Genes such as $p 16$, p15, GSTP1, SOCS-1, RASSF1A, and APC play an important role in HCC development (Narimatsu et al.

\section{里}


2004; Yang et al. 2003; Tischoff \& Tannapfel 2008). These genes are involved in the regulation of the cell cycle, xenobiotic metabolism, suppression of cytokine signaling, apoptosis, and cell migration. Most DNA methylation studies have concentrated on genes mainly inactivated by hypermethylation of normally unmethylated CpG islands containing promoter regions. However, some researchers have shown that $\mathrm{CpG}$ hypermethylation in nonpromoter regions is sometimes associated with the upregulation of gene expression (Smith et al. 2007). Shinojima et al. and Watanabe et al. recently reported aberrant methylation in candidate human genomic regions that was identified through the analysis of skin tumor-specific differentially methylated regions in mouse models using the restriction landmark genomic scanning (RLGS) method. They examined differentially methylated regions in the exon of zygote arrest 1 (ZAR1) that had never been linked to aberrant methylation in melanomas and brain tumors (Shinojima et al. 2010; Watanabe et al. 2011). Here, we detected aberrant methylation of the nonpromoter region of ZAR1 in hepatitis $C$ virus-positive $\mathrm{HCC}$ tissues compared with nontumorous liver and metastatic liver cancer tissues.

\section{Results and discussion}

The methylation level of CpG islands in ZAR1 exon 1 (RLGS spot 5D52) was analyzed in $88 \mathrm{HCV}$-positive HCC and 4 normal liver tissues, which were circumjacent to colon cancer liver metastasis. The average methylation level of all CpG sites in Zar1 in each individual was calculated, and 67 of 88 cases showed a significantly higher methylation level in HCC than in nontumorous tissue $(p<0.05)$ (Figure 1). The average methylation level of each CpG site in Zar1 of all 88 cases are shown in Figure 2. All CpG sites showed a significantly higher methylation level in HCC than in the matched nontumorous tissues $(p<0.05)$. Because it is already known that HCV-positive nontumorous tissues undergo some epigenetic changes, we also compared the methylation level of Zar1 in normal liver tissues with that in $\mathrm{HCV}$-positive nontumorous tissues; however, no difference was found between the tissues (data not shown).

The hypermethylation group was defined as the sample set in which patients' cancer tissues showed a twofold or higher methylation level of ZAR1 compared with nontumorous liver tissues. A total of 22 and 66 patients were enrolled in hypermethylation hypomethylation groups, respectively. When the background clinicopathological features of the hypermethylation and hypomethylation groups were compared using univariate analysis, there were significant differences in levels of serum AFP $(p=0.018)$ and albumin $(p=0.001)$ and tumor multiplicity $(p=0.031)$ (Table 1). Multivariate regression analyses were performed to identify which of the following factors were the predictors of hypermethylation: serum albumin, AFP, and tumor multiplicity. The presence of low serum albumin level increased the risk for hypermethylation $(p=0.007)$ (Table 2).

These results demonstrated that DNA methylation levels of ZAR1 were significantly different between HCVrelated $\mathrm{HCC}$ and nontumorous tissues. Most studies on the analysis of DNA methylation in cancer genomes have focused on promoter $\mathrm{CpG}$ island methylation and examined only restricted sets of CpG sites in their target regions. To identify genome-wide aberrant methylation in mouse skin cancer tissues, we previously performed RLGS analysis and then confirmed the results using MassARRAY EpiTYPER. The RLGS method can semiquantitatively detect the change in methylation level of NotI in global genomic regions, including the regions outside the promoter. MassARRAY EpiTYPER can quantitatively analyze the methylation level of CPG sites by basespecific cleavage in combination with MALDI-TOF-MS detection. Using these methods, we were able to detect a differentially methylated region in the exon of ZAR1 that had never been identified as an aberrantly methylated region in clinical HCC tissue samples (Shinojima et al. 2010; Smiraglia et al. 2007). Our findings clearly showed that aberrant hypermethylation of the ZAR1 nonpromoter region was common in many HCV-related HCC tissues.

ZAR1 is an ovary-specific maternal factor that has critical importance in the initiation of embryogenesis (Wu et al. 2003). Mouse and human ZAR1 protein contain 361 and 424 amino acids, respectively, and have $59 \%$ similarity in amino acid sequence. Although the ZAR1 protein is not a member of any characterized protein family, it contains an atypical plant homeodomain (PHD) finger in its C-terminus. PHDs are found in two major classes of proteins, such as transcriptional activators, repressors, or cofactors and subunits of complexes that modulate chromatin (Wu et al. 2003). ZAR1 may be a transcriptional regulator, and the conserved $Z A R 1 \mathrm{C}$-terminus is probably important for its function. Shinojima et al. analyzed malignant melanomas and reported that tumorspecific methylation of $\mathrm{CpG}$ islands in ZAR1 that were located downstream from the promoter region was associated with an increased expression level of the ZAR1 transcript. Although they transfected the full-length ZAR1 cDNA plasmid into normal melanocytes and also performed knock down of ZAR1 expression in melanoma cells using siRNA, no differences were observed in either the cell growth rate or the morphology of the transfected cells (Shinojima et al. 2010). In the present study, the hypermethylation group, whose cancer tissues showed a twofold or higher methylation level compared with nontumorous liver tissues, showed a significantly higher level of serum AFP $(p=0.018)$ and lower level of serum albumin $(p=0.001)$ compared with the hypomethylation group, using univariate analysis. In addition, all the patients in the hypermethylation group developed only 


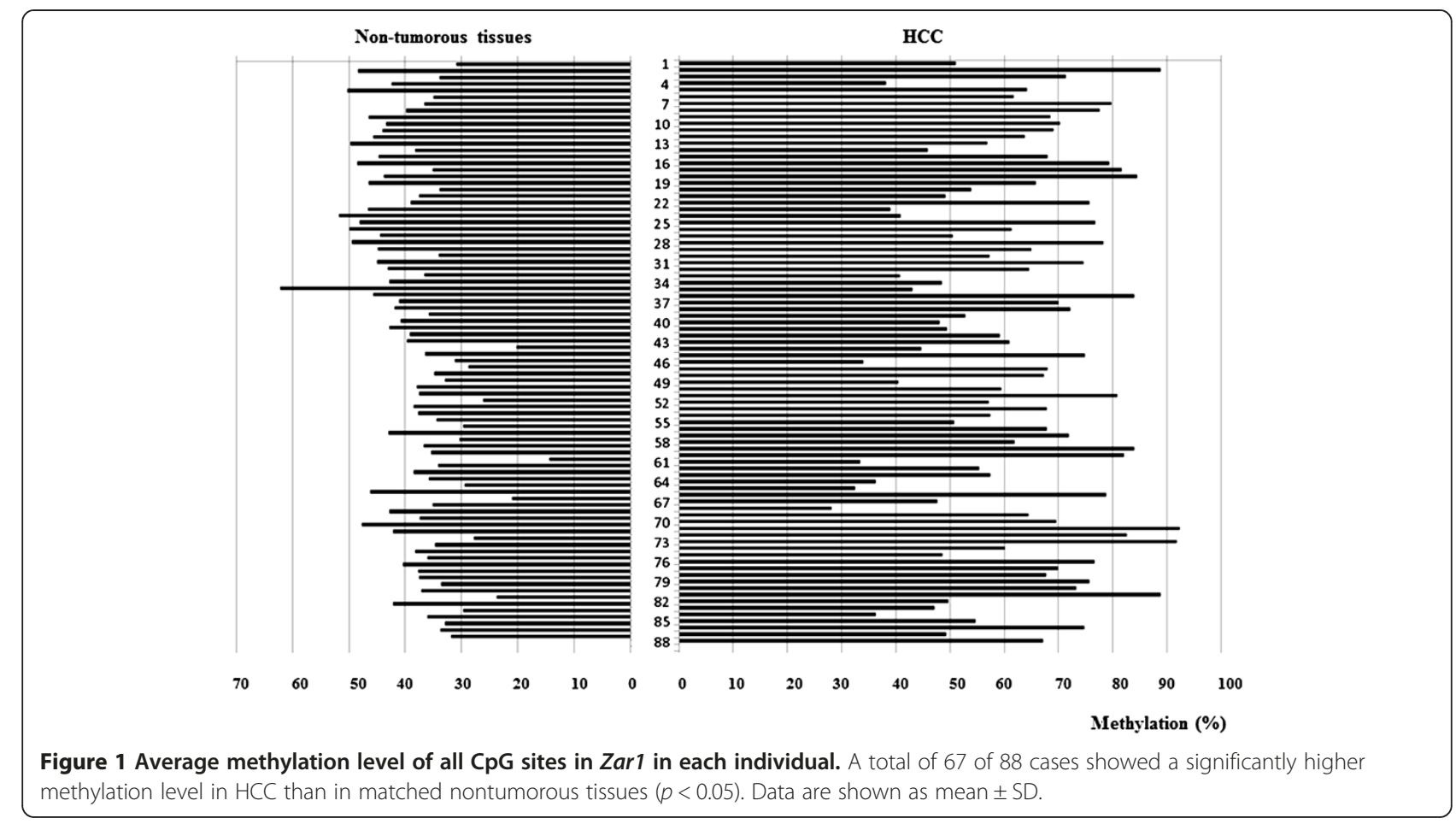

single, but not multiple, tumors $(p=0.031)$. Multivariate regression analyses were performed to identify the predictors of the hypermethylation group. The patient with low serum albumin level had an increased risk for hypermethylation $(p=0.007)$. In general, it was already known that a high serum AFP level and low serum albumin level are associated with development and poor prognosis of HCC (Tateyama et al. 2011; Ueno et al. 2002).
Albumin is a group of proteins produced mainly in the liver. Because the method for measurement of albumin concentration is simple and easy, the serum albumin level has been used as a prognostic factor following liver resection. However, owing to the long half-life of albumin, it is not a sensitive marker to detect events changing over a short period (Shirabe et al. 2011; Horino et al. 2012). In this study, the mean values of methylation level of all CpG sites

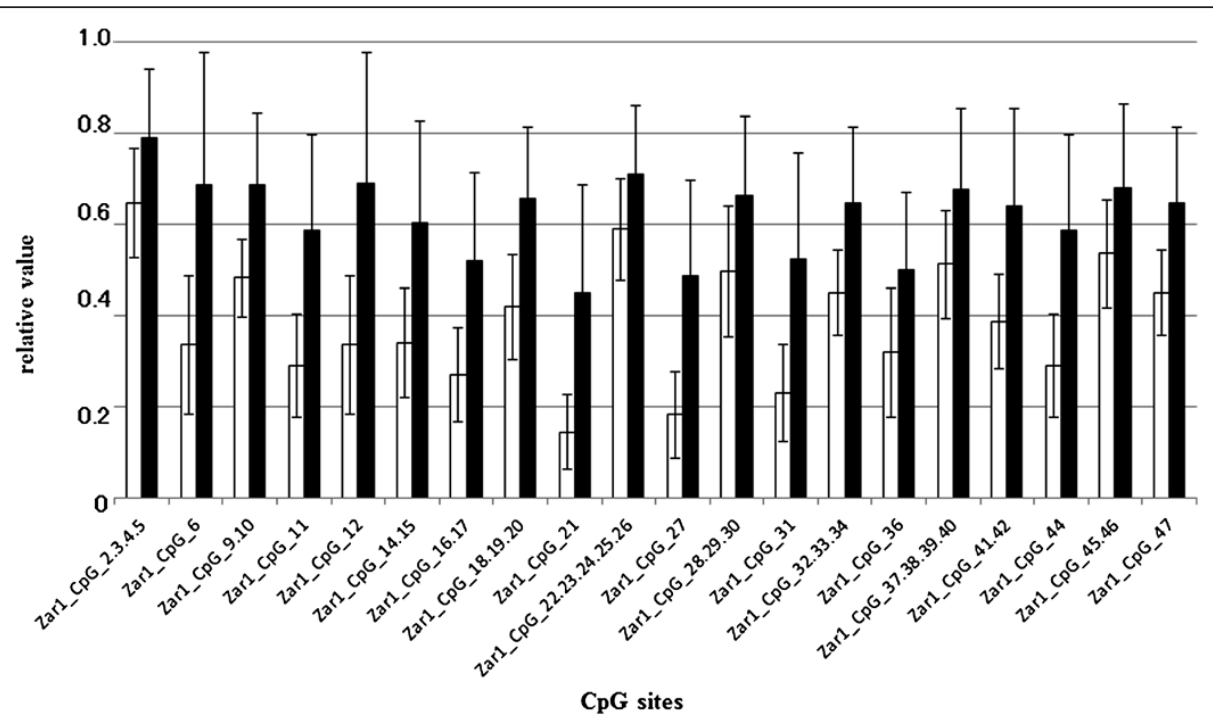

Figure 2 Average methylation level of each CpG site in Zar1 in HCC and nontumorous liver tissues. Open bars indicate nontumorous tissues, and filled bars indicate HCC tissues. All CpG sites showed a significantly higher methylation level in HCC than in nontumorous tissues $(p<0.05)$. Data are shown as mean \pm SD. 
Table 1 Comparison of clinicopathological features between the 2 groups

\begin{tabular}{|c|c|c|c|c|}
\hline Variable & & Hypermethylation group $n=22(\%)$ & Hypomethylation group $n=66(\%)$ & $P$ \\
\hline \multirow[t]{2}{*}{ Gender } & M & $17(77.3)$ & $58(87.9)$ & 0.225 \\
\hline & $\mathrm{F}$ & $5(22.7)$ & $8(12.1)$ & \\
\hline Age $(y)^{a}$ & & $65.8(50.0-78.0)$ & $68.5(50.0-78.0)$ & 0.07 \\
\hline \multirow[t]{2}{*}{ ICG15R (\%) } & $<10$ & $6(27.3)$ & $26(39.4)$ & 0.306 \\
\hline & $\geqq 10$ & $16(72.7)$ & $40(60.6)$ & \\
\hline \multirow[t]{2}{*}{ Alb (g/dl) } & $<3.5$ & $9(40.9)$ & $6(9.1)$ & 0.001 \\
\hline & $\geqq 3.5$ & $13(59.1)$ & $60(90.9)$ & \\
\hline \multirow[t]{2}{*}{ AST (U/l) } & $<40$ & $7(31.8)$ & $21(31.8)$ & 1.000 \\
\hline & $\geqq 40$ & $15(68.2)$ & $45(68.2)$ & \\
\hline \multirow[t]{2}{*}{ ALT (U/I) } & $<40$ & $9(40.9)$ & $27(40.9)$ & 1.000 \\
\hline & $\geqq 40$ & $13(59.1)$ & $39(59.1)$ & \\
\hline \multirow[t]{2}{*}{ T.Bil (mg/dl) } & $<1.2$ & $20(90.9)$ & $59(89.4)$ & 0.839 \\
\hline & $\geqq 1.2$ & $2(9.1)$ & $7(10.6)$ & \\
\hline \multirow[t]{2}{*}{ AFP (ng/ml) } & $<20$ & $8(36.4)$ & $42(63.6)$ & 0.018 \\
\hline & $\geqq 20$ & $14(63.6)$ & $24(36.4)$ & \\
\hline non-LC & & $10(45.5)$ & $41(62.1)$ & 0.170 \\
\hline LC & & $12(54.5)$ & $25(37.9)$ & \\
\hline \multirow[t]{2}{*}{ Vascular invasion } & $(+)$ & $10(45.5)$ & $43(65.2)$ & 0.102 \\
\hline & $(-)$ & $12(54.5)$ & $23(34.8)$ & \\
\hline \multirow[t]{2}{*}{ Tumor multiplicity } & single & $22(100)$ & $54(81.8)$ & 0.031 \\
\hline & multiple & $0(0)$ & $12(18.2)$ & \\
\hline \multirow[t]{2}{*}{ Liver damage } & A & $15(68.2)$ & $38(57.6)$ & 0.379 \\
\hline & B & $7(31.8)$ & $28(42.4)$ & \\
\hline \multirow[t]{2}{*}{ Recurrence } & $(+)$ & 19 (86.4) & $52(78.8)$ & 0.436 \\
\hline & $(-)$ & $3(13.6)$ & $14(21.2)$ & \\
\hline
\end{tabular}

Data are given as median (range).

ICG15R, indocyanin green retention rate at 15 min; Alb, albumin; AST, aspartate aminotransferase; ALT, alanine aminotransferase; T.Bil, total bilirubin; AFP, alpha fetoprotein; LC, liver cirrhosis.

in HCC tissues were higher, and the presence of low serum albumin level increased the risk for hypermethylation $(p=0.007)$. For these reasons, it is suggested that ZAR1 hypermethylation could be a novel and good marker to detect HCC and also could be a potential marker for HCC prognosis.

ZAR1 mRNA expression was not detected in any of the tissue specimens in this study. There is a possible explanation for this result. The aberrant hypermethylation of ZAR1 may be the result of a secondary effect of the tumorigenesis process, or the methylation level of Zar1 exon 1 may be involved in the regulation of other genes distant from Zar1. Further studies are needed to

Table 2 Independent risk factors predicting hypermethylation in multivariate logistic regression analysis

\begin{tabular}{lccc}
\hline & Odds ratio & $\mathbf{9 5 \%} \mathrm{Cl}$ & $\boldsymbol{p}$ \\
\hline Alb $(\mathrm{g} / \mathrm{dl})<3.5$ & 5.921 & $1.643-21.335$ & 0.007 \\
\hline
\end{tabular}

understand the role of hypermethylation of the Zar1 genomic region in HCC development.

\section{Conclusions}

This study showed that the methylation level of the Zar1 genomic region is higher in HCV-related HCC than in nontumorous tissues and that patients with Zar1 hypermethylation had a significantly lower serum albumin level than those from the hypomethylation group. Although it is still unknown how ZAR1 hypermethylation affects HCC development, it could be a marker for HCVrelated HCC and also could be a potential marker for predicting HCC prognosis.

\section{Methods}

Patients and tissue samples

Eighty-eight hepatitis $\mathrm{C}$ virus-positive $\mathrm{HCC}$ and matched nontumorous tissue and four normal liver tissues, which were circumjacent to tissues of metastatic liver cancer, 
were obtained from the Nihon University Hospital, Japan, from 1995 to 2010. Informed consent was obtained from all patients. All liver tissue specimens were immediately frozen in liquid nitrogen and stored at $-80^{\circ} \mathrm{C}$ until use. Nontumorous tissues were excised with sufficient margins from the cancer. This study was approved by the Institutional Review Boards of Nihon University School of Medicine.

\section{DNA extraction and bisulfite treatment}

DNA was extracted using the standard phenol-chloroform purification method or a QIAamp DNA Mini Kit (Qiagen, Valencia, CA, USA). Bisulfite modification of DNA was performed using an EZ DNA Methylation Gold Kit (Zymo Reseach, Orange, CA, USA). Bisulfitetreated genomic DNA was amplified using HotStar Taq Polymerase (Qiagen) for $15 \mathrm{~min}$ at $94^{\circ} \mathrm{C}$ followed by 45 cycles of $20 \mathrm{~s}$ at $94^{\circ} \mathrm{C}, 30 \mathrm{~s}$ at $56^{\circ} \mathrm{C}$, and $1 \mathrm{~min}$ at $72^{\circ} \mathrm{C}$, with a 3 -min final extraction at $72^{\circ} \mathrm{C}$. The polymerase chain reaction (PCR) products obtained were subjected to gel electrophoresis and then measured using Sequenom MassARRAY.

\section{Quantitative methylation analysis using base-specific cleavage and matrix-assisted laser desorption/ionization time-of-flight mass spectrometry (MALDI-TOF-MS)}

A Sequenom MassARRAY quantitative DNA methylation analysis was performed (Ehrich et al. 2005) using the MassARRAY Compact System. This system is based on mass spectrometry (MS) for the detection and quantitative analysis of DNA methylation using homogeneous MassCLEAVE (hMC), base-specific cleavage, and matrixassisted laser desorption/ionization time-of-flight MS (MALDI-TOF MS) (Ehrich et al. 2005). The ZAR1 primer was designed using Methyl Primer Express ${ }^{\circledR}$ Software to span the closely adjacent DMRs or the GC rich region, as indicated. The primers used for the quantitative ZAR1 methylation analysis were designed to anneal to the 374-bp bisulfite-treated fragment for the MassARRAY EpiTYPER (Sequenom, San Diego, CA, USA). The reverse primer has a T7-promoter tag for in vitro transcription $\left(5^{\prime}\right.$-cagtaatacgactcactatagggagaaggct- $\left.3^{\prime}\right)$, and the forward primer is tagged with a decamer to balance the temperature $(\mathrm{Tm})\left(5^{\prime}\right.$-aggaagagag- $\left.3^{\prime}\right)$. These primers were purchased from Operon (Tokyo, Japan). PCR amplification was performed using HotStar Taq Polymerase (Qiagen) in a $5-\mu l$ reaction volume using PCR primer at a final concentration of $200 \mathrm{nM}$ and $1 \mu \mathrm{l}$ of bisulfitetreated DNA ( 20 ng/ml). After treatment with shrimp alkaline phosphatase, $2-\mu \mathrm{l}$ aliquots of the PCR products were used as a template for in vitro transcription and RNase A cleavage for the T-reverse reaction, as described in the manufacturer's instructions (Sequenom $\mathrm{hMC}$ ). The samples were desalted and spotted on a 384-pad SpectroCHIP (Sequenom) using a MassARRAY nanodispenser (Samsung, Seoul, Korea) followed by spectral acquisition on a MassARRAY Analyzer Compact MALDI-TOF MS (Sequenom). The resultant methylation calls were analyzed using EpiTYPER software v1.0 (Sequenom) to generate quantitative measurements for each CpG site or an aggregate of multiple CpG sites. A standard curve of quantitative DNA methylation analysis was constructed using $0 \%, 50 \%$, and $100 \%$ methylated samples. The amplified DNA was not methylated at all in any of the CpG sites and was used as unmethylated (0\%) control. M.SssI double-treated DNA was prepared according to the manufacture's protocols (New England Biolabs, Ipswich, MA, USA) at $37^{\circ} \mathrm{C}$ for $1 \mathrm{~h}$ followed by inactivation at $65^{\circ} \mathrm{C}$ for 20 min for $100 \%$ methylation samples. By mixing equal amounts of $0 \%$ and $100 \%$ control samples, the $50 \%$ methylation samples were prepared. The standard curve was fitted, and methylation levels were adjusted and quantified.

\section{Statistical analysis}

Comparison of clinicopathological features between the hypermethylation and hypomethylation groups was analyzed by Fisher's exact test or Mann-Whitney $U$ test. Methylation levels of HCV-related HCC and metastatic liver cancer tissues were compared using the $t$-test. Statistical analysis was performed using SPSS version 15.0 (SPSS Inc., Chicago, IL, USA). Differences were considered significant at $p<0.05$.

\section{Abbreviations}

HCC: Hepatocellular carcinoma; RLGS: Restriction landmark genomic scanning; ZAR1: Zygote arrest 1.

\section{Competing interests}

The authors declare that they have no competing interests.

\section{Authors' contributions}

KT performed the analysis of genome DNA methylation and the statistical analysis and drafted the manuscript, KF designed the study and helped to draft the manuscript, TT and TM collected and evaluated the surgical tissue specimens, MS participated in designing the study and drafting the

manuscript, and HN conceived the study. All authors read and approved the final manuscript.

\section{Acknowledgments}

This work was mainly supported by a Grant-in-Aid for Scientific Research (A) 24249068 from the Ministry of Education, Culture, Sports, Science and Technology (MEXT), Japan, to TT; the Nihon University Multidisciplinary Research Grant for 2007; the Academic Frontier Project for 2006 Project for Private Universities; and a matching fund subsidy from MEXT to HN., MEXTSupported Program for the Strategic Research Foundation at Private Universities (2011-2015) to M.S., K.F., T.T. The authors thank their colleagues from the Department of Digestive Surgery.

\section{Author details}

'Department of Digestive Surgery, Nihon University School of Medicine, 30-1 Oyaguchi-Kamicho, Itabashi-ku, Tokyo 173-8610, Japan. ${ }^{2}$ Innovative Therapy Research Group, Nihon University Research Institute of Medical Science, Nihon University School of Medicine, 30-1 Oyaguchi-Kamicho, Itabashi-ku, Tokyo 173-8610, Japan. ${ }^{3}$ Division of General Medicine, Department of Medicine, Nihon University School of Medicine, 30-1 Oyaguchi-Kamicho, 
Itabashi-ku, Tokyo 173-8610, Japan. ${ }^{4}$ Chiba Cancer Center Research Institute, 666-2 Nitona-cho, Chuo-ku, Chiba-shi, Chiba 260-8717, Japan.

Received: 5 January 2013 Accepted: 4 April 2013

Published: 10 April 2013

\section{References}

Ehrich M, Nelson MR, Stanssens P, Zabeau M, Liloglou T, Xinarianos G, Cantor CR, Field JK, van den Boom D (2005) Quantitative high-throughput analysis of DNA methylation patterns by base-specific cleavage and mass spectrometry. Proc Natl Sci USA 102:15785-15790

Horino K, Beppu T, Kuroki H, Mima K, Okabe H, Nakahara O, Ikuta Y, Chikamoto A, Ishiko T, Takamori H, Baba H (2012) Glasgow prognostic score as a useful prognostic factor after hepatectomy for hepatocellular carcinoma. Int J Clin Oncol 21, doi:10.1007/s10147-012-0451-3

Ikai I, Arii S, Okazaki M, Okazaki M, Okita K, Omata M, Kojiro M, Takayasu K, Nakanuma Y, Makuuchi M, Matsuyama Y, Monden M, Kudo M (2007) Report of the 17th Nationwide follow-up survey of primary liver cancer in Japan. Hepatol Res 37:676-691

Kawashima H, Sugito K, Yoshizawa S, Uekusa S, Furuya T, Ikeda T, Koshinaga T, Shinojima Y, Hasegawa R, Mishra R, Igarashi J, Kimura M, Wang X, Fujiwara K, Gosh S, Nagase H (2012) DNA hypomethylation at the ZNF206-exon 5 CpG island associated with neural differentiation in mice and development of neuroblastoma in humans. Int J Oncol 40:31-39

Makuuchi M, Takayama T, Kubota K, Kimura W, Midorikawa Y, Miyagawa S, Kawasaki S (1998) Hepatic resection for hepatocellular carcinoma - Japanese experience. Hepatogastroenterology 45(Suppl3):1267-1274

Narimatsu T, Tamori A, Koh N, Kubo S, Hirohashi K, Yano Y, Arakawa T, Otani S, Nishiguchi S (2004) p16 promoter hypermethylation in human hepatocellular carcinoma with or without hepatitis virus infection. Intervirology 47:26-31

Shinojima Y, Terui T, Hara H, Kimura M, Igarashi J, Wang X, Kawashima H, Kobayashi Y, Muroi S, Hayakawa S, Esumi M, Fujiwara K, Ghosh S, Yamamoto T, Held W, Nagase H (2010) Identification and analysis of an early diagnostic marker for malignant melanoma: ZAR1 intra-genic differential methylation. J Dermatol Sci 59:98-106

Shirabe K, Takeishi K, Taketomi A, Uchiyama H, Kayashima H, Maehara Y (2011) Improvement of long-term outcomes in hepatitis $\mathrm{C}$ virus antibody-positive patients with hepatocellular carcinoma after hepatectomy in the modern era. World J Surg 35:1072-1084

Smiraglia DJ, Kazhiyur-Mannar R, Oakes CC, Wu YZ, Liang P, Ansari T, Su J, Rush LJ, Smith LT, Yu L, Liu C, Dai Z, Chen SS, Wang SH, Costello J, loshikhes I, Dawson DW, Hong JS, Teitell MA, Szafranek A, Camoriano M, Song F, Elliott R, Held W, Trasler JM, Plass C, Wenger R (2007) Restriction landmark genomic scanning (RLGS) spot identification by second generation virtual RLGS in multiple genomes with multiple enzyme combinations. BMC Genomics 30:446

Smith JF, Mahmood S, Song F, Morrow A, Smiraglia D, Zhang X, Rajput A, Higgins MJ, Krumm A, Petrelli NJ, Costello JF, Nagase H, Plass C, Held WA (2007) Identification of DNA methylation in 3' genomic regions that are associated with upregulation of gene expression in colorectal cancer. Epigenetics 2:161-172

Tateyama M, Yatsuhashi H, Taura N, Motoyoshi Y, Nagaoka S, Yanagi K, Abiru S, Yano K, Komori A, Migita K, Nakamura M, Nagahama H, Sasaki Y, Miyakawa Y, Ishibashi H (2011) Alpha-fetoprotein above normal levels as a risk factor for the development of hepatocellular carcinoma in patients infected with hepatitis C virus. J Gastroenterol 46:92-100

Tischoff I, Tannapfel A (2008) DNA methylation in hepatocellular carcinoma. World J Gastroenterol 14:1741-1748

Ueno S, Tanabe G, Nuruki K, Oketani M, Komorizono Y, Hokotate H, Fukukura Y, Baba Y, Imamura Y, Aikou T (2002) Prognosis of hepatocellular carcinoma associated with Child class B and C cirrhosis in relation to treatment: a multivariate analysis of 411 patients at a single center. J Hepatobiliary Pancreat Surg 9:469-477

Watanabe T, Yachi K, Ohta T, Fukushima T, Yoshino A, Katayama Y, Shinojima Y, Terui T, Nagase H (2011) Non-promoter hypermathylation of zygote arrest 1 (ZAR1) in human brain tumors. Brain Tumor Pathol 28:199-202
Wu X, Viverious MM, Eppig JJ, Bai Y, Fitzpartrick SL, Matzuk MM (2003) Zygote arrest 1 (Zar1) is a novel maternal-effect gene critical for the oocyte-to embryo transition. Nature Genet 33:187-191

Yang B, Guo M, Herman JG, Clark DP (2003) Aberrant promoter methylation profiles of tumor suppressor genes in hepatocellular carcinoma. Am J Pathol 163:1101-1107

doi:10.1186/2193-1801-2-150

Cite this article as: Takagi et al: DNA hypermethylation of zygote arrest 1 (ZAR1) in hepatitis $C$ virus positive related hepatocellular carcinoma. SpringerPlus 2013 2:150

\section{Submit your manuscript to a SpringerOpen ${ }^{\odot}$ journal and benefit from:}

- Convenient online submission

- Rigorous peer review

- Immediate publication on acceptance

- Open access: articles freely available online

- High visibility within the field

- Retaining the copyright to your article

Submit your next manuscript at $\gg$ springeropen.com 